Journal of Arts

Cilt / Volume 2, Say1 / Issue 1, 2019, pp. 37-46

E - ISSN: 2636-7718

URL: http://ratingacademy.com.tr/ojs/index.php/arts

DOI: $10.31566 /$ arts.2.003

Araştırma Makalesi / Research Article

\title{
GIORGIONE, TIZIANO, MANET: ÜÇ SANATÇI, ÜÇ VENÜS
}

\author{
GIORGIONE, TIZIANO, MANET: THREE ARTISTS, THREE VENUS
}

\author{
Erdal KARA* \\ * Dr. Öğr. Üyesi., Mimar Sinan Güzel Sanatlar Üniversitesi, Güzel Sanatlar Fakültesi, Resim Bölümü, \\ TÜRKIYE, E-mail: erdal.kara@msgsu.edu.tr, \\ ORCID ID: https://orcid.org/0000-0002-0375-4321
}

Geliş Tarihi: 16 Aralık 2018; Kabul Tarihi: 29 Ocak 2019

Received: 16 December 2018; Accepted: 29 January 2019

\section{$\ddot{O Z Z E T}$}

Uzanan nü, sanat tarihinde pek çok defa betimlenmiş, klasikleşmiş bir konudur. Bu türün, başyapıt niteliğindeki üç örneği, Giorgione'nin Uyuynan Venüs'ü, Tiziano'nun Urbino Venüsü ve Edouard Manet'nin Olympia'sıdır. Bu üç resmin en önemli ortak noktası ve aynı konudaki diğer resimlerden ayrllan özelliği birbirlerinden türetilmiş olmalarıdır. Rönesans'ın Venedikli ustalarından biri olan Giorgione'nin Uyuyan Venüs resmi, doğal kadın güzelliğini yüceltmiş, aşk tanrıçası Venüs'ü idealize etmistir. Giorgione’nin yakın dostu Tiziano, Uyuyan Venüs'ün biçimsel özellikleriyle, Urbino Venüsü olarak adlandırılan resmini oluşturmuştur. Biçimsel olarak idealize edilmiş olan Venüs, içerik olarak insani duygular yansıtmaktadır. Uzanmış nü figürü izleyici ile doğrudan temas kurduran Tiziano, bu resimde aşk ve sadakate dair bir alegori yaratmıştır. 19. yüzyılın önemli Fransız ressamı Edouard Manet, Urbino Venüsü’nü yeniden yorumladiğ bir uzanan nü resmetmiştir. Manet, Olympia adını verdiği bu resimde, aşk tanrıçasını, bir hayat kadını olarak betimlemiştir. Gerçekçi ve doğal bir biçimsel yaklaşımla oluşturulmuş olan resim, klşkıtıcı özellikleriyle dikkat çekmektedir. Aynı konunun ele alındı̆̆ bu üç resim, sanatta biçim ve ifadenin değişimiyle içeriğin de değiştiğini gösteren örnek durumundadır. Bu çalışmada, her üç resim, biçim ve içerik iliş̧kisi açısından incelenerek, resimlerin verdiği mesajlar irdelenmiş, tüm ortak unsurlara rağmen, eserlerin içerdiği anlam farklılıklarına nasıl ulaşıldı̆̆ı ortaya konulmuştur.

Anahtar Kelimeler: Resim, Nü, Venüs, Giorgione, Tiziano, Manet

\section{ABSTRACT}

The reclining nude is a classic theme depicted in art history many times. Three masterpieces of this genre are the Sleeping Venus of Giorgione, the Venus of Urbino of Tiziano and the Olympia of Edouard Manet. The most important common point of these three paintings and the fact that they are separated from the other pictures in the same subject is that they are derived from each other. One of 
the Venetian masters of the Renaissance, Giorgione's Sleeping Venus picture, glorified the natural beauty of woman, idealized the goddess of love Venus. Giorgione's close friend Tiziano, with the formal characteristics of the Sleeping Venus, formed the picture of the Venus of Urbino. Venus, formally idealized, reflects human emotions as content. Tiziano, who directly contacted the audience with his reclining nude, created an allegory of love and loyalty in this picture. Edouard Manet, an important French painter of the nineteenth century, depicted a nude he had reinterpreted the Venus of Urbino. In this picture, which he called Olympia, Manet described the goddess of love as a prostitute. Created with a realistic and natural formal approach, the painting draws attention with its features. These three pictures, which deal with the same subject, illustrate how the content has changed with the change of form and expression in art. In this sttudy, all three paintings were analyzed in the term of the relationship between form and content and the messages given by the paintings were examined and it was revealed how the meaning difference in the works were reached despite all common elements.

Keywords: Painting, Nude, Venus, Giorgion, Tiziano, Manet.

\section{GíRiș}

Antik Yunan dininin en önemli mitolojik kişiliklerinden birisi aşk tanrıçası Afrodit’tir. Yunan kültüründe idealize edilmiş bir biçimde pek çok sanat eserinin konusu olan Afrodit, diğer tüm mitolojik karakterler gibi, zaman içinde Roma dininin ve kültür hayatının da bir parçası haline gelmiştir. Roma'da Latince Venüs adını alan aşk tanrıçası, farklı sanat eserlerinde önemli bir yer edinmiştir. Hristiyanlığın M.S. 4.yüzyılda Roma İmparatorluğu'nun resmi dini olmasından sonra, mitolojik kişiliklerin sanatsal betimlemeleri ortadan kalkmıştır. Fakat Rönesansın ortaya çıkışı ile antik bilgiler ve mitoloji yeniden gündeme gelmiştir. Böylece Venüs karakterinin de 15.yüzyıl İtalyan sanatında konu edilmeye başlandığ 1 görülmektedir. $\mathrm{Bu}$ dönemin en öne çıkan eseri Sandro Botticelli'nin aşk tanrıçasını resmettiği “ Venüs'ün doğuşu” adlı tablodur. Venüs'ün doğuşu işlediği mitolojik konunun yanı sıra M.Ö. 1. yüzyılda yapılmış ve aynı adı taşıyan Pompeii duvar resmiyle ilintili olmasıyla da dikkat çekmektedir (Morgan, 11.12.2018). Botticelli tıpkı Pompeii resmindeki gibi Venüs'ü bir istiridye kabuğunun içinde doğarken betimlemiş ve yanına diğer mitolojik karakterleri eklenmiştir, Fakat Pompeii'de Venüs uzanmış bir figür olması ve ayak ucunda Cubid'in bulunması ile bir farklılık oluştururken, Botticelli'nin resminde sağda ilkbahar tanrıçası Hora, solda Aura ve rüzgar tanrısı Zefir yer almaktadır. Botticelli Venüs'ün doğuşu ve Venüs'ü resmettiği diğer büyük kompozisyon olan “İlkbahar" ile Rönesans'da diğer ressamların benzer temaları ele almalarının yolunu açmıştır. 
Resim 1. Pompeii duvar resmi, “Venüs'ün doğuşu”. M.Ö. 1.yüzyıl

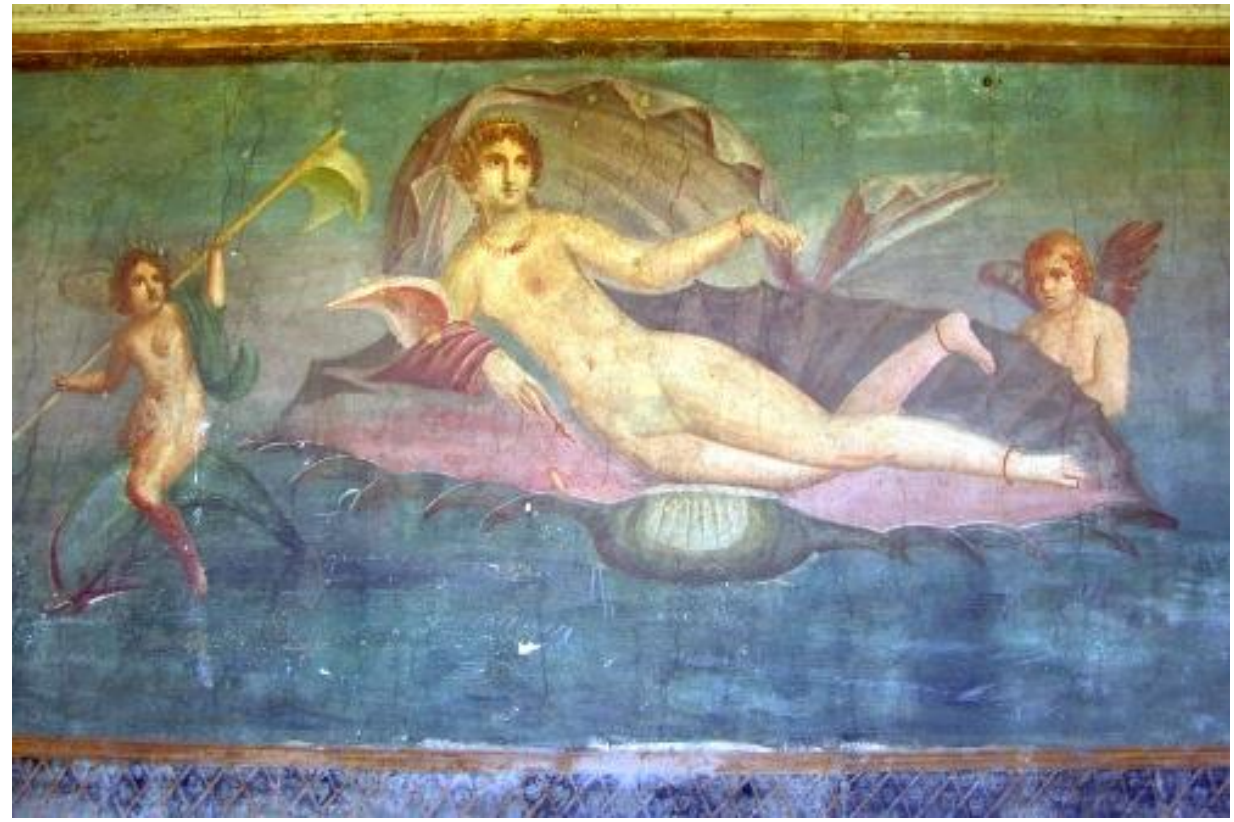

Kaynak. https://uwaterloo.ca

Resim 2. Sandro Botticelli, "Venüs'ün doğuşu”. 1485

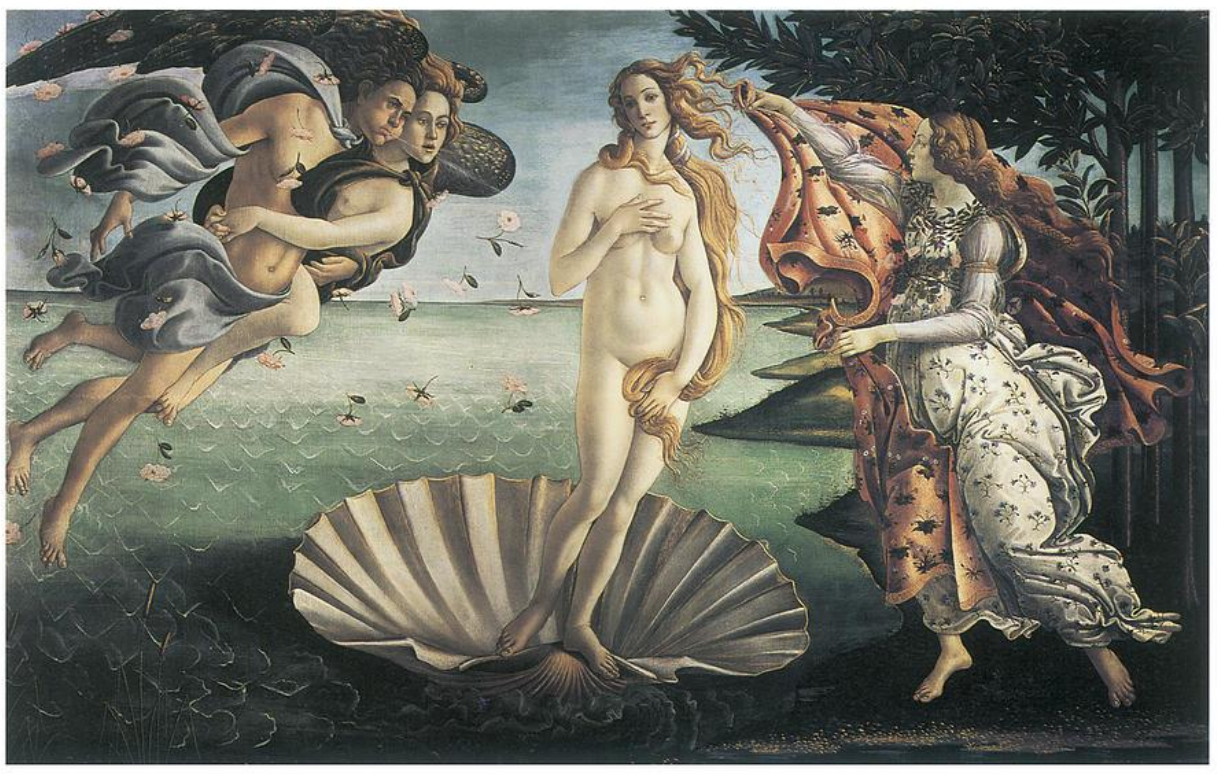

Kaynak. https://www.wga.hu/art/b/botticel/5allegor/30birth.jpg

Botticelli' in etkilediği ressamların başında Venedik resminin önemli ustası Giorgione gelmektedir. Giorgione "Uyunan Venüs" ile Rönesans resminin ilk uzanan nü ${ }^{1}$ tablosunu yapmış ve böylece sanatta çağlar boyunca devam edecek bir türün doğmasına sebep olmuştur

Nü: Sanatta çıplak insan bedeni betimleyen eserlere verilen ad. 
(Ferrara-Borzello, 2002, 6). Uzanan nü, pek çok önemli ressam tarafından farklı dönemlerde ele alınan klasikleşmiş bir konu halini almıştır. Sanat tarihinde resmedilen bu resimlerden biri Giorgione'nin yakın arkadaşı Tiziano tarafından yapılmış “Urbino Venüsü” olarak adlandırılan tablodur. Uyuyan Venüs resmine de doğrudan katk1 sağlayan Tiziano, elde ettiği tecrübelerini kendi resmine taşıyarak, iki resmi birbiriyle ilintili bir duruma getirmiştir. 19. yüzyılda, Fransız ressam Edouard Manet, Urbino Venüsü ile aynı pozda betimlediği bir uzanmış nü resmeder. Olympia adındaki bu tablo, Tiziano'nun resminin modern bir yansıması durumundadır. Bunun sonucunda da sanat tarihinin bu üç önemli eseri arasında bir bağlantı oluşmuştur. Aralarındaki ortak noktaların içine yerleştirilmiş olan farklılıklar ikonagrafi, biçim ve ifade açısından incelendiğinde, her bir resmin özgün niteliği belirginleşmektedir.

\section{GIORGIONE, UYUYAN VENÜS}

Kısa bir kariyeri olan, fakat buna rağmen yeteneği ve geride biraktığı eserleriyle Venedik resim ekolünün önemli bir ustası olarak görülen Giorgione'nin 1510 yılında yaptığı "Uyuyan Venüs", Rönesans sanatının önemli resimlerinden biri kabul edilmektedir. Asıl adı Giorgio Barbarelli da Castelfranco olan Giorgione, Giovanni Bellini’nin öğrencisi olmuş ve 33 yaşında hayattan ayrılması ile geride bitmemiş bazı resimler de bırakmıştır. Bu resimlerden biri de Uyuyan Venüs'tür. Giorgione'nin kendisi için yaptığı bu resim ölümünden sonra yakın dostu Tiziano tarafından tamamlanmıştır (Kaminski, 1998: 10).

$108,5 \times 175 \mathrm{~cm}$ boyutlarındaki tuval üzerine yağlı boya resim günümüzde Almanya'nın Dresden şehrindeki Gemaldegalerie'de_sergilenmektedir. Resimde Venüs açık, pastoral bir manzaranın önünde çimlerin üstüne serili kumaşlara uzanmış bir şekilde uyuyorken betimlenmektedir. Bir eli başının altında, diğer eli ise kasığını kapatan figür tamamen çıplak bir durumdadır. Vücut hareketi gergin bir yay biçimini almış olan Venüs yüzü izleyiciye dönük olarak gösterilmiştir. Giorgione aslında uzanış nü figürün ayak ucunda, ona eşlik eden bir Cubid resmetmiş fakat bu figürün üstü 1843 yılında boyanarak kapatılmıştır (Alexson, 11.12. 2013).

Giorgione aşk tanrıçasının vücut kıvrımları ile doğanın görünümünü özdeşleştirmiştir. Böylece daha önceki resimlerinde var olan, doğa-insan birlikteliğini, aşk temasıyla yeniden yorumlamış ve kadın güzelliğini idealize etmiştir. Bununla birlikte resmin yapıldığ dönemde Venedik Cumhuriyeti komşuları ile toprak sorunları yaşamaktaydı. Venedik adı Venüs'ün İtalyanca söyleniş şekli olan Venere ile simgeselleştirildiğinden bu resmin politik bir içerik barındırdığı da düşünülmektedir (Web Gallery of Art, 11.12.2018). Uyuyan Venüs, duruşu ve ifadesiyle izleyiciyle arasına mesafe koymakta, adeta bir dokunulmazlığa sahip olmaktadır. 
Resim 3. Giorgione, Uyuyan Venüs, 1510.

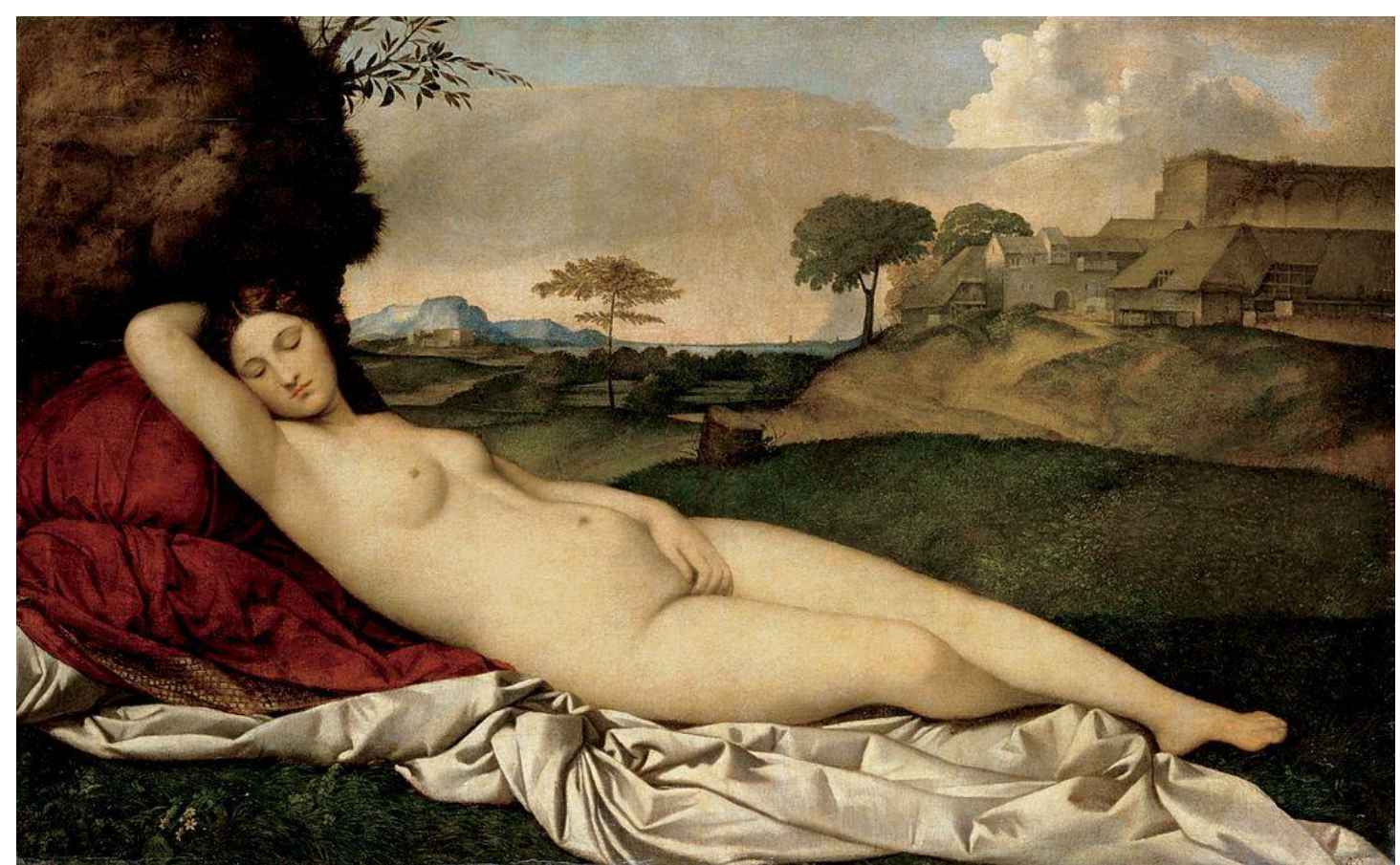

Kaynak. https://www.wga.hu/art/g/giorgion/various/venus.jpg

\section{TIZIANO, URBINO VENÜSÜ}

Venedik resminin bir diğer büyük ustası ve Giorgione'nin yakın dostu olan Tiziano "Urbino Venüsü” olarak adlandırılan resmi 1538 yılında tamamlamıştır. Resim ilk bakışta Uyuyan Venüs'e benzerliği ile dikkat çekmektedir. Bir iç mekanda, yatağa uzanmış olan çıplak kadın figürünün göğsünden ayaklarına kadar olan kısmı Uyuyan Venüs ile hemen hemen aynı biçimde resmedilmiştir. Yatağın kırmızı döşemesi ve beyaz çarşaf da bu benzerliği destekleyen unsurlardır. Tiziano figürü, Giorgione gibi yay biçiminde bir poz içinde betimlemiştir. Bununla birlikte iki resim arasında ciddi farklar da bulunmaktadır. Çıplak figür bir kolunu yastığın üstüne koymuş ve elinde bir gül tutmaktadır. Ayak ucunda bir sadakati simgeleyen köpek uyumakta, geri planda ise iki hizmetçi zengin bir malikhaneye ait olduğu belli olan odadaki sandıkları düzenlemektedir. Bütün bunların ötesinde, figür doğrudan izleyiciye bakarak göz teması kurmakta, yüz ifadesi, omzuna dökülen saçları ve aksesuarları ile belirgin bir kimlik oluşturmaktadir.

119x165 cm boyutlarında, tuval üzerine yağlıboya resim günümüzde Floransa'nın Uffizi Galerisi'nde sergilenmektedir. Resmin neden yapıldığı hakkında çeşitli söylenceler kayitlara geçmiş olmakla birlikte, en çok kabul edilen görüş, Urbino Dükü Francesco Maria della Rovere'nin varisi Guidobaldo della Rovere için yapılmış olduğudur. Guidobaldo'nun Giuliana Varano ile 1534 yılında yaptığı evlilikle ilişkilendirilen resmin, tutkulu aşk ve sadakate dair bir alegorik kompozisyon olduğu görülmektedir (Kaminski,1998: 63).

Tiziano Venüs'ü klasik sanatın biçimsel idealizsyonu ile resmetmesine rağmen içerik olarak idealize etmemiştir. Venüs dokunulmaz, yüce bir tanrıça olmaktan çok, cinsel çağrışımlar içeren ifadesiyle genç bir kadındır. Davetkar bakışları izleyici ile doğrudan bir iletişim kurmakta ve böylece aradaki mesafeyi azaltmaktadır. 
Resim 4. Tiziano, Urbino Venüsü, 1534.

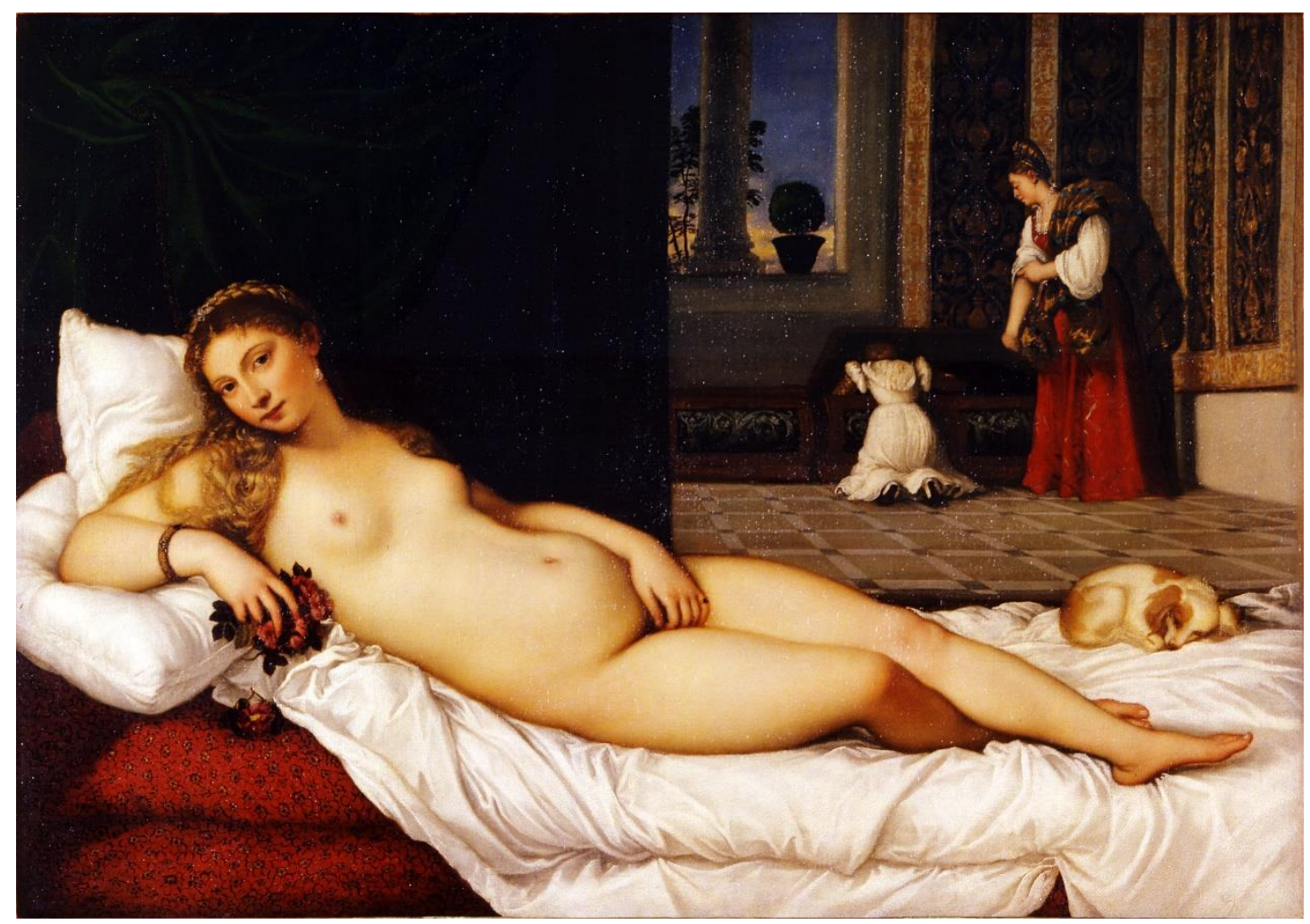

Kaynak. https://www.wga.hu/art/t/tiziano/08/08urbin.jpg

\section{EDOUARD MANET, OLYMPIA}

Tiziano'nun Urbino Venüsü tablosu, 19. yüzyıl Fransız resminin önemli ustası Edourad Manet'ye ilham kaynağı olmuştur (Reff, 1976: 48). Manet, 1863 yılında Olympia adlı resmiyle Urbino Venüsü'nü yeniden yorumlamıştır (Neret, 2003: 21). Resim çıplak bir genç kadını üzerinde yastıklar olan bir yatağa uzanmış bir halde betimlemektedir. Kadına siyahi bir hizmetçi bir buket çiçek getirmekte, ayak ucunda da bir kara kedi yer almaktadır.

130,5 x190 cm boyutlarında tuval üzerine yağlı boya resim günümüzde Paris'de Orsay Müzesi'nde sergilenmektedir. Olympia ilk defa 1865 yılında Paris Salonu'nda sergilenmiş, üslubu ve alışılmadık içeriğiyle bir skandala sebep olmuştur. İzleyiciler tarafından tepki ile karşılanmasının sebebi, uzanmış nü figürün bir tanrıçayı değil bir hayat kadınını resmetmiş olmasıdır. Çıplak kadın, pozu, aksesuarları ve izleyici ile kurduğu göz kontağı sayesinde kendi kimliğini açıklamakta, siyahi hizmetçi ise getirdiği çiçek buketi ile bu sahneyi tamamlamaktadır. Urbino Venüsü'nde yer alan sadakat sembolü uyuyan köpeğin yerini alan kara kedi, uğursuzluk ve şeytani olanı temsil etmektedir (Neret, 2003: 21). Bütün bu unsurlar ile resmin kışkırtıcı bir özelliğe sahip olduğu açıtır.

Manet'nin resmi biçimsel olarak gerçekçi bir üsluba sahiptir. Çıplak kadın figürü, Rönesans resimlerinin aksine, idealize edilmemiştir. Biçimsel yaklaşım, resmin içeriği ile de desteklenmekte, klasik sanatın aşk tanrıçası Venüs, modern sanatta dünyevi bir kişiliğe sahip Olympia'ya dönüşmektedir. Emil Zola Olympia için şöyle söylemektedir: " Sanatçılarımız bize Venüs'ler verdiğinde doğayı düzelip, yalan söylerler. Edouard Manet kendine, neden yalan söyleyeyim diye sordu, neden gerçeği söylemeyeyim. Bizi kaldırımda yürürken karşılaştığınız zamanımızın kızı Olympia ile tanıştırdı" (Simonsen et al, 2004: 79) 
Resim 5. Edouard Manet, Olympia, 1863

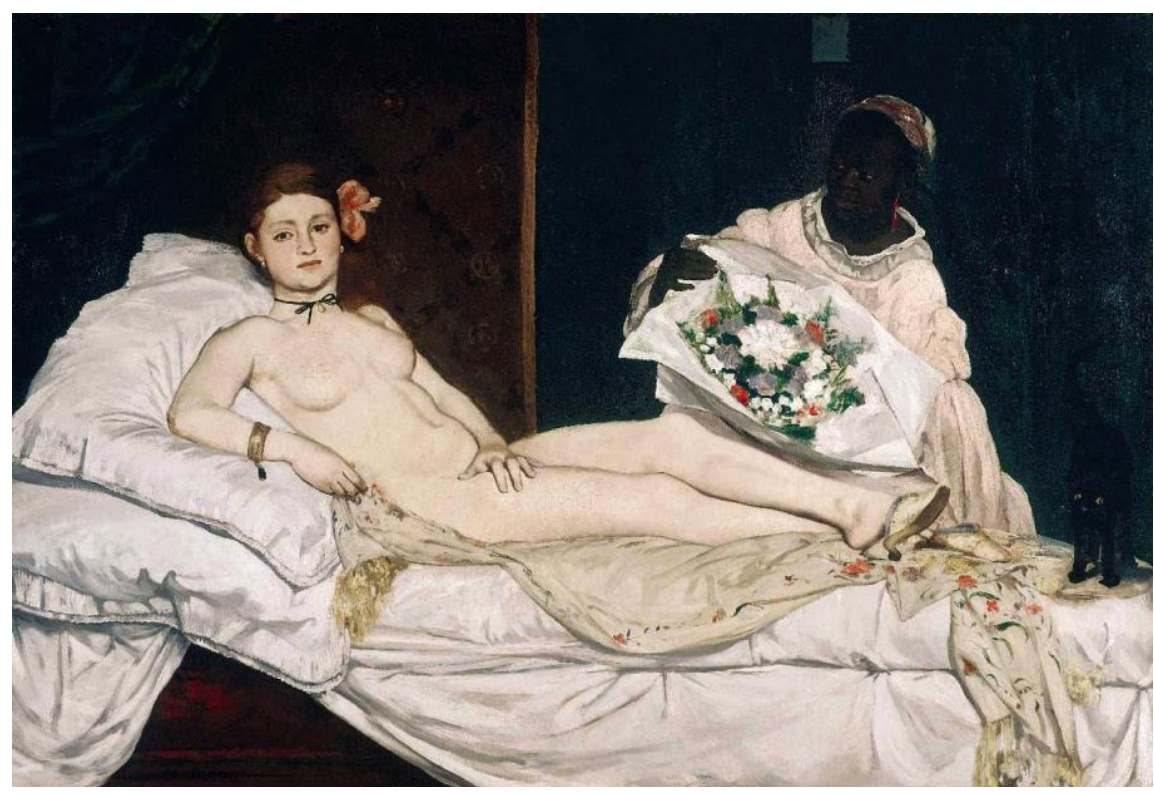

Kaynak. https://www.wga.hu/art/m/manet/1/4olympil.jpg

\section{SONUÇ}

Sanat tarihinde birbirlerinden etkilenerek oluşmuş pek çok eser vardır ve bunların bir kısmı başyapıt niteliği taşımaktadır. Uyuyan Venüs, Urbino Venüsü ve Olympia arasındaki ilişki çok farklı bir yere sahip olmuştur. Çünkü resimler sıra ile, doğrudan birbirlerinden doğmuşlar ve dönüşüm geçirerek özgünleşmiş̧lerdir.

Tiziano, Giorgione'nin resmini tamamlarken elde ettiği deneyimi Urbino Venüsü'nü yaratırken kullanmıştır. Uyuyan Venüs'ün ana konusunu ve figürün biçimsel özelliğini kendi resmine bire bir geçirmiştir. Giorgione'nin doğa ile birlikte ele aldığı kadın güzelliğini yüceltmesi ve Venüs'ü kişilik olarak idealize etmesi, Tiziano'nun resminde görülmez. Tiziano Urbino Venüsü'nü evlilik esnasında geline hediye edilen bir resim aracılığıyla, erkeğin kadına vermek istediği mesajları çeşitli simgelerle anlatmak isteyen "cassaone" geleneği içinde kurgulamıştır (Florence, 14.12. 2018). Kadın figürü sahip olduğu ifade ile oldukça insani bir duygusal derinlik oluşturmaktadır.

Tiziano'dan üç yüzyıl sonra Edouard Manet, Urbino Venüsü'nü yeniden ele alarak Olympia'yı yaratmıştır. Manet Olympia ile, aşk tanrıçasını, genç bir hayat kadınına, idealize edilmiş biçimi, gerçekçi ve doğal bir biçimsel yapıya dönüştürerek, hem kavramsal, hem de görsel bir derinlik yaratmıştır. Bu resimde antik dünyaya ait yücelik kavramı yok olmakta, onun yerini 19. yüzyıl modernizminin dünyevi gerçekçiliği almaktadır. 
Resim 6. Olympia (solda) ve Urbino Venüsü (sağda), Dükalık Sarayı, Venedik, 2013.

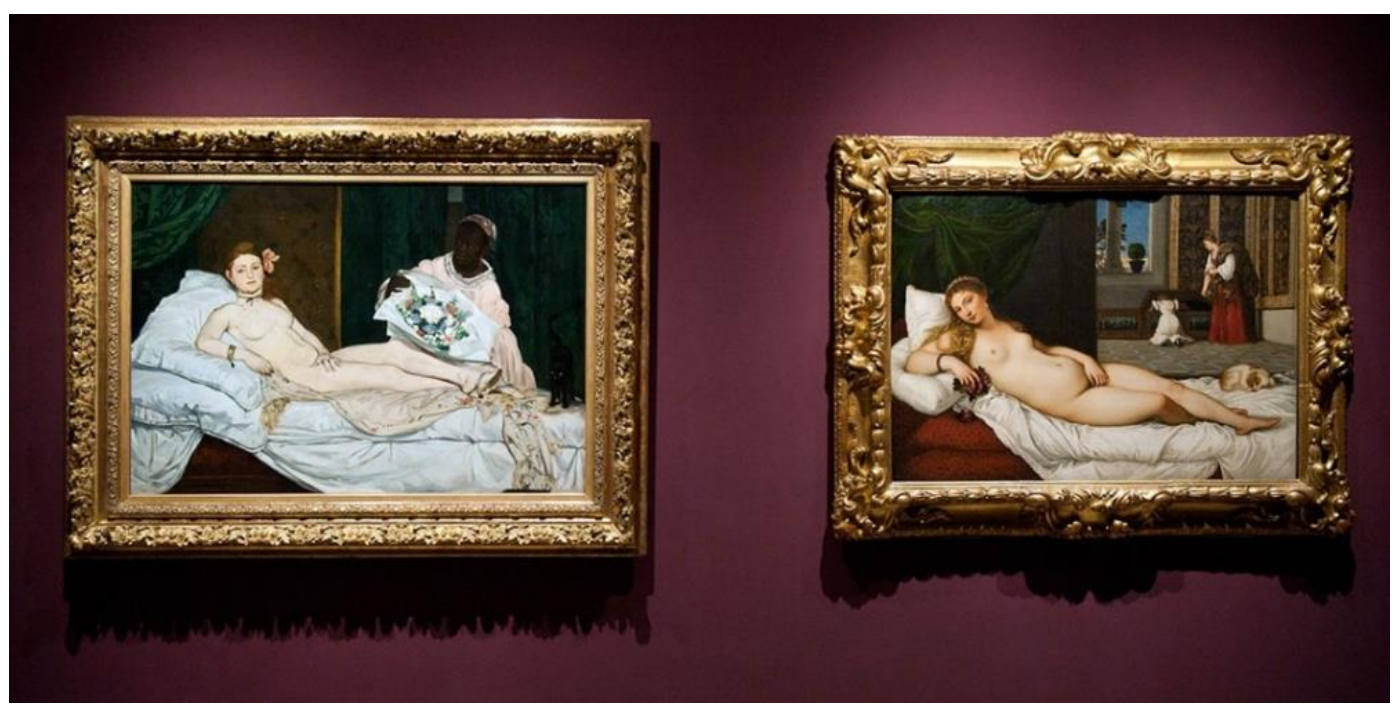

Kaynak. theperrynews.com

Aynı konuyu ele alan üç resim, biçim ve ifadedeki değişiklikler aracılığıyla, birbirlerinden çok farklı içeriğe sahip olmuşlardır. Bunun sebebi Giorgione, Tiziano ve Manet'nin dünya görüşlerinin ve vermek istedikleri mesajların farklılığıdır. Her bir resim, kendi mesajını uzanmış nü konusunun içinde kalarak, fakat ayrıntılarda farklılıklar yaratarak oluşturmuş, böylece özgün bir yapıt halini alabilmiştir. Bu bakımdan, Uyuyan Venüs, Urbino Venüsü ve Olympia sanatta biçimsel ifadenin içerik oluşturmasına iyi birer örnek durumundadir. 


\section{KAYNAKÇA}

ALEXSON. Kendra, 2013, Giorgione's Sleeping Venus: Function, Influences and Inspiration [online] Washington State University, Pullman, Washington, https://s3.wp.wsu.edu/uploads/sites/458/2013/05/Kendra-Alexson-Research-1.pdf [Erişim Tarihi: 11.12.2018]

FERRARA. Lidia Guilbert-BORZELLO. Frances, 2002, Reclining Nude, Thames \& Hudson Ltd, London, ISBN 0-300-23797-2

FLORENCE, 2018, Venere di Urbino [online] https://www.florence.net/galleria-degliuffizi/quadro-venere-di-urbino-galleria-degli-uffizi.aspx [ErişimTarihi:14.12.2018]

KAMINSKI. Marion, 1998, Titian, Könemann Verlagsgesellschaft mbH, Cologne, ISBN 38290-0257-2

MORGAN.Alan V, 2006, Naples and Mt. Vesuvius [online] University of Waterloo, https://uwaterloo.ca/wat-on-earth/news/naples-and-mt-vesuvius [ErişimTarihi:11.12.2018]

NERET. Gilles, 2003, Manet, Taschen GmbH, Köln, ISBN 3-8228-1949-2

REFF. Theodore, 1976, Manet: Olympia, Allen Lane, London, ISBN 0713908076

SIMONSEN. Karen-Magrethe, HUANG. Marianne Ping, THOMSEN. Mads Rosendahl, 2004, Reinventions of The Novel, Rodopi, Amsterdam-New York, ISBN 90-420-0843-1

WEB GALLERY OF ART, 2018, Sleeping Venus [online] https://www.wga.hu/html m/g/giorgion/various/venus.html [Erişim Tarihi: 11.12.2018] 
KARA / Giorgione, Tiziano, Manet: $\ddot{U} c ̧$ Sanatçı, Üç Venüs 